\title{
Ecotoxicities of emulsifiable concentrate and granules of cinnamon (Cinnamomum zeylanicum) essential oil against Cyprinus carpio and Danio rerio
}

\author{
Tae-Hoon Nam ${ }^{1} \cdot$ Hwang-Ju Jeon ${ }^{1} \cdot$ Kyeongnam Kim ${ }^{1} \cdot$ Hyeong-Mi Kim $^{1}$. \\ Yong-Chan Kim ${ }^{1}$ - Sung-Eun Lee ${ }^{1}$ (D)
}

\section{계피(Cinnamomum zeylanicum) 정유의 유제 및 입제의 잉어(Cyprinus carpio) 및 제브라피쉬에 대한 생태독성}

남태훈 · 전황주 · 김경남 · 김형미 · 김용찬 · 이성은

\begin{abstract}
In this study, cinnamon essential oil (CEO) was formulated as emulsifiable concentrate (EC) and a granule. For the evaluation of their negative effects on the ecosystem, acute toxicities against Cyprinus carpio was determined in a static condition. The formulations were made using CEOs extracted by 3 different methods (steam distillation (SD), solvent extraction and supercritical fluid extraction (SFE)) and were tested to obtain $\mathrm{LC}_{50}$ values. Among the ECs, EC including CEO extracted by SFE showed highest acute toxicity against $C$. carpio. Among the granules, a granule including $\mathrm{CEO}$ extracted by $\mathrm{SD}$ showed highest acute toxicity against $C$. carpio. Nevertheless, $\mathrm{LC}_{50}$ of EC and a granule formulation with CEOs was higher than toxicity level III of pesticide standardized by Korea rural development administration. These results were similar to those using zebrafishes. Chronic toxicities were not found for 45 days in zebrafishes until $500 \mu \mathrm{gL}^{-1}$ level of EC formulation including CEO obtained by the SD. Based on these results, EC formulation of CEOs may be considered to be used as environmental-friendly

Sung-Eun Lee $(\bowtie)$

E-mail: selpest@knu.ac.kr

${ }^{1}$ School of Applied Biosciences, Kyungpook National University, Daegu 41566, Korea

This is an Open Access article distributed under the terms of the Creative Commons Attribution Non-Commercial License (http://creativecommons. org/licenses/by-nc/3.0/) which permits unrestricted non-commercial use, distribution, and reproduction in any medium, provided the original work is properly cited.
\end{abstract}

natural insecticides in accordance with the standards.

Keywords Acute toxicity $\cdot$ Chronic toxicity $\cdot$ Cinnamon essential oil - Cyprinus carpio $\cdot$ Danio rerio $\cdot$ Emulsifiable concentrate

\section{서 론}

계피(Cinnamomum verum) 나무껍질로부터 추출한 정유 (Essential oils)는 향신료로 주로 사용되어지고 민간치료요법에 서도 이용되어왔다[1]. 이들 정유는 식중독을 일으키는 다양한 박테리아에 대하여 항균활성이 뛰어나며 아플라톡신(Aflatoxins) 을 생산하여 식품 및 저장 곡물에 주로 오염시키는 Aspergillus flavus 또는 A. fumigatus 등의 곰팡이에 대한 살균 또는 생장 억제 효과를 지니고 있다고 보고되었다[2,3]. 이들의 동물에 대 한 생리활성은 당뇨병 쥐의 총 콜레스테롤 함량, 저밀도지질 (low-density lipids) 및 중성지방(triglycerides)의 농도를 조절하 는 기능이 알려졌다[4]. 흥미롭게도 대부분의 계피의 생리활성 은 주로 정유형태로 존재할 때 보고된 바가 많으며 이들은 상 업적으로도 쉽게 구입할 수 있다[1,2,3].

계피정유는 주로 수증기증류법(steam distillation)으로 추출되 어지며 이들의 주요성분으로는 모노테르펜으로서 cinnamaldehyde 가 약 $92 \%$ 정도 존재하는 것으로 보고되었다[5]. 이 계피 정유 의 항균작용으로는 균 세포안의 전해질의 누설현상 유도 및 대 사작용의 저하로서 확인되었으며[5], 이러한 항균작용과 더불어 옥수수바구미(Sitophilus zeamais)에 대한 살충 및 기피작용을 나 
타내었다[6]. 살충효과는 농업해충에서도 발견되었으며 실험에 사용된 농업해충으로는 복숭아혹진딧물(Myzus persicae), 배추좀 나방(Plutella xylostella), 및 점박이 응애(Tetranychus urticae) 등이었다[7]. 이러한 살충효과를 보고한 논문은 특이하게도 정 유를 세가지 다른 방법을 이용하여 추출하였으며 이는 수증기 증류법, 용매추출법(solvent extraction), 및 초임계추출법 (supercritical extraction) 등이었다[7]. 수증기증류법 및 헥산을 이용한 용매추출법으로 추출한 계피정유는 각각 복숭아혹진딧 물에 대해서 5.96 및 $4.64 \mu \mathrm{g} / \mathrm{cm}^{2}$ 의 살충효과를 나타내었다[7].

그러나, 정유는 강한 휘발성분인 모노테르펜으로 주로 구성 되어 있으므로 이들을 쉽게 농업적인 목적으로 사용하기 어려 운 단점이 있다. 이러한 단점을 극복하여 이들을 농업 해충 등 을 박멸하기 위한 제형으로 여러 제형 형태를 개발하였다. 키 토산을 이용한 나노캡슐화[8] 방법 및 유제화하여 사용하는 방 법등이 고안되었다[9,10]. 또 다른 형태의 제형으로 최근에는 halloysite 나노튜브에 정유를 캡슐화한 후 이들의 방출량을 조 절한 경우가 보고되었다[11].

국내에서는 이러한 정유의 제형을 농업적인 목적으로 사용하 기 위하여 이 제형의 안전성(safety)를 시험해야 하며 주로 비 표적(non-target) 곤충인 꿀벌 및 민물에 서식하는 잉어 및 미꾸 라지를 활용한다[12, 13]. 따라서, 본 연구는 다양한 추출방법으 로 얻은 계피정유의 각각의 두 제형(입제와 유제)에 대한 잉어 (Cyprinus carpio)를 이용한 급성독성(acute toxicity), 잉어 및 제브라피쉬(Danio rerio)를 이용한 만성독성(Chronic toxicity), 마지막으로 꿀벌(Apis mellifera)을 이용한 엽상잔류독성 (honeybee acute and residual toxicity)을 실험하여 이들 정유의 제형이 생태 및 환경에 미칠 영향을 평가하였다.

\section{재료 및 방법}

\section{시험물질}

시험에 사용된 계피 정유는 전북대학교 이회선교수께서 수증기 증류법, 핵산을 이용한 용매추출법, 그리고 초임계 추출법을 이 용하여 추출한 정유를 제공받아 사용하였다. 상용화된 계피 정 유를 Mother and Daughters(포천, 경기도)사로부터 구입하여 사 용하였다. 사용된 유화제로는 Castor oil, Tween 80, Triton X100 , Tergitol, Nonidet 등의 비이온계 계면활성제와 음이온성 계 면활성제로서 Sodium dodecyl sulfate (SDS)와 sodium dodecyl benzene sulfonate 등의 2종이 사용되었으며 모두 SigmaAldrich사(St Louise, MO, USA)로부터 구입하였다.

\section{시험생물}

본 어독성 실험에 사용된 잉어(Cyprinus carpio)는 오창양어장 (오창, 충북, 대한민국)으로부터 구입하여 경북대학교 실험실에 서 1주일 이상 순화시킨 것으로 사용하였다. 실험에 사용된 잉 어의 전장은 최소 $3-5 \mathrm{~cm}$ 로 건강한 개체를 선별하였다. 시험 실 시 24시간 전부터 잉어에 대한 먹이공급을 중단하고 사용된 물 은 염소를 제거한 상태의 물을 사용하였다.

\section{유제 및 입제의 제조}

유제의 품질관리를 위해 정유의 비중들을 측정하였고 그를 바
탕으로 유제의 비중들을 측정하였다. 정유 유제를 제형화하기 위하여 에탄올을 용제로 사용하였고 유화제와의 최종 제형 비 를 5:1:4 (정유 : 유화제 : 에탄올)로 설정하여 제조하였다. 비이 온성 계면활성제는 이온성 계면활성제에 비하여 피부자극이 적 고 유효성분에 영향을 끼치지 않는 것으로 알려져 있다. Tergitol 를 선정하여 실험을 수행하였다[13]. 계면활성제가 물과 기름에 대한 친화성 정도를 나타내는 값인 $\mathrm{HLB}$ 값의 범위가 8 에서 15 사이인 비이온성 계면활성제를 사용하였고, 선택한 계면활성제 는 미국 EPA LIST 3, 4에 농약의 보조제로서 사용이 허가되 어 있다.

Zeolite를 사용하여 유제를 흡유시켜 입제를 제조하였으며 입 제의 입자별 중량과 흡유능을 고려하여 Zeolite의 적정크기를 설정하였다. 선택한 담체는 미국 EPA LIST 3, 4에 농약의 보 조제로서 사용가능 하였고, Zeolite의 흡유능에 따라 최종 제형 비를 1:9 (유제 : Zeolite)가 되도록 제조하였다.

\section{계피정유 원제, 유제, 입제의 잉어에 대한 급성어독성 실험} 농촌진흥청 환경생물 독성 시험기준과 방법(제 5 조 제 1 항 제 4 호) 에 따라 잉어에 대한 급성독성실험을 실시하였다. 계피원제의 잉어급성독성 실험을 위해 수증기, 핵산, 초임계 추출법을 이용 하여 획득한 정유와 아세톤을 무게비 50:50으로 혼합하였다. 추 출법 별로 유효성분이 $10 \mathrm{mg} \mathrm{L}^{-1}$ 이 되도록 처리할 경우 사용되 는 계면활성제 양을 계산하여 Tergitol을 사용하여 급성독성시 험을 실시하였다.

계피 원제의 잉어급성독성 실험결과에 따라 수증기 증류법으 로 추출된 계피정유는 유효성분이 $6,8,10,11,12,13,15$, $20 \mathrm{mg} \mathrm{L}$ 이 되도록 처리하여 총 9개의 시험군으로 나누어 급 성독성시험을 실시하였다. 계피 원제의 잉어급성독성 실험결과 에 따라 핵산 추출된 계피정유는 유효성분이 $6,8,10,12,15$, $20 \mathrm{mg} \mathrm{L}^{-1}$ 이 되도록 처리하여 총 6 개의 실험군으로 나누어 급 성독성시험을 실시하였다. 계피 원제의 잉어급성독성 실험결과 에 따라 초임계 추출법으로 추출된 계피정유는 유효성분이 6 , $8,10,15,20 \mathrm{mg} \mathrm{L}^{-1}$ 이 되도록 처리하여 총 5 개의 실험군으로 나누어 급성독성시험을 실시하였다.

\section{계피정유 유제의 제브라피쉬 치어에 대한 급성어독성 실험}

수증기 증류법으로 추출한 계피 유제의 제브라피시 성체에 대 한 급성독성은 제형화한 유제를 유효성분이 $0.5,1,1.5,2,2.5$, $5,7.5,10,12.5 \mathrm{mg} \mathrm{L}^{-1}$ 이 되도록 처리하여 총 9 개의 실험군으 로 나누어 급성독성시험을 실시하였다. 실험실에서 계대 사육 및 순화시킨 제브라피시를 전장 $3 \mathrm{~cm}$ 의 건강한 개체를 선별하 여 독성실험에 사용하였다. 실험 24시간 전부터 먹이공급을 중 단하였으며, 염소를 제거한 수돗물 $3 \mathrm{~L}$ 를 $3 \mathrm{~L}$ 비커에 채워 20 28 도의 온도를 유지하여 각 비커 당 10 마리의 제브라피시를 처 리하여 지수식으로 실험을 96시간 동안 수행하였다. 실험도중 의 치사개체는 발견 즉시 제거하였으며, 치사량을 24 시간 단위 로 측정하여 총 96시간 동안 기록하였다. 비커내의 용존산소량, $\mathrm{pH}$, 온도는 24시간 단위로 총 96시간 동안 측정하여 기록하였 다.

\section{계피 유제의 제브라피시 배아에 대한 생육초기독성}

수증기 추출한 고수 유제의 제브라피시 배아 생육초기독성 실 
험을 위해 수증기 추출법을 이용한 고수 정유를 사용해 제형화 한 유제를 유효성분이 $10,50,100,250,500 \mathrm{mg} \mathrm{L}^{-1}$ 가 되도록 처리하여 총 5 개의 실험군으로 나누어 생육초기독성시험을 실 시하였다. 실험실에서 계대 사육 및 순화시킨 제브라피시의 배 아 중 산란된 시간이 6시간 이상 차이나지 않는 건강한 개체를 선별하여 독성실험에 사용하였다. Egg water (천일염 $1 \%$ 수용 액)를 패트리디시에 채워 20-28도의 온도를 유지하여 각 패트 리디시 당 30마리를 처리하여 반지수식으로 실험을 72 시간 동 안 수행하였다. 72 시간 동안 부화 및 생존한 치어는 72 시간 경 과 후 염소를 제거한 수돗물 $2 \mathrm{~L}$ 를 $3 \mathrm{~L}$ 비커에 채워 20-28도의 온도를 유지하여 반지수식으로 실험을 7일 동안 수행하였다. 실 험도중의 치사개체는 발견 즉시 제거하였으며, 치사량 및 부화 율을 24 시간 단위로 측정하여 치사량은 10 일 그리고 부화율은 72시간 동안 기록하였다. 각 패트리디시 및 비커의 물은 24시 간마다 갈아주었으며, 하루에 2회 이상 먹이(브라인슈림프)를 급 여하였다. 페트리디시 및 비커 내의 용존산소량, $\mathrm{pH}$, 온도, 경 도, 알칼리도는 24 시간 단위로 총 10 일 동안 측정하여 기록하 였다.

\section{계피 수증기 중류 추출 정유 유제의 제브라피시에 대한 만성독 성 실험}

수증기 추출한 계피 유제의 제브라피시 성체 만성독성 실험을 위해 수증기 증류추출법을 이용한 계피 정유를 사용해 제형화 한 유제를 유효성분이 $10,50,100,250,500 \mathrm{mg} \mathrm{L}^{-1}$ 가 되도록 처리하여 총 5 개의 실험군으로 나누어 시험을 실시하였다. 구 입한 제브라피시를 실험실에서 1 주일 이상 순화시킨 후, 전장 $2-3 \mathrm{~cm}$ 의 건강한 개체를 선별하여 독성실험에 사용하였다. 염소 를 제거한 수돗물 $3 \mathrm{~L}$ 를 $3 \mathrm{~L}$ 비커에 채워 $20-28$ 도의 온도를 유 지하여 각 비커 당 10 마리의 제브라피시를 처리해 반지수식으 로 실험을 45 일 동안 수행하였다. 각 비커의 물은 일주일에 3 회 갈아주었으며 하루에 2회 이상 먹이(브라인슈림프)를 급여하 였다. 페트리디시 및 비커 내의 용존산소량, $\mathrm{pH}$, 온도, 경도, 알 칼리도는 물을 갈아줄 때마다 총 45 일 동안 측정하여 기록하 였다.

\section{통계분석}

실험에서 얻어진 결과 값은 통계프로그램(SPSS)의 프로빗(Probit) 프로그램을 이용하여 $95 \%$ 신뢰한계에서 반수치사농도 $\left(\mathrm{LC}_{50}\right)$ 를 구하였다. 실험군 간의 유의성을 비교하기 위하여 $t$-test $(p$ $>0.05$ )를 수행하였다.

\section{결과 및 고찰}

잉어에 대한 계피정유 원제의 급성독성은 Table 1에 나타내었 다. 수증기 증류법으로 추출된 정유의 경우 48 시간 동안의 $\mathrm{LC}_{50}$ 값이 $10.48 \mathrm{mg} \mathrm{L}^{-1}(\mathrm{ppm})$ 수준이었으며 96시간 동안 노출 시켰 을 때에도 같이 동일한 농도 수준을 유지하였다. 이는 48시간 이후 96시간까지 치사개체가 발견되지 않았기 때문이다. 핵산 을 이용한 용매 추출법으로 획득한 계피정유의 경우 48 시간 동 안 노출시켰을 때 $\mathrm{LC}_{50}$ 값이 $11.55 \mathrm{mg} \mathrm{L}{ }^{-1}$ 으로 96 시간 노출시 켰을 때의 $\mathrm{LC}_{50}$ 값과 동일하였다. 이러한 결과를 토대로 계피
Table 1 Acute toxicity of cinnamon essential oils to carps (Cyprinus carpio)

\begin{tabular}{ccc}
\hline \hline Technical products & $\begin{array}{c}48 \mathrm{~h} \mathrm{LC}_{50}\left(\mathrm{mg} \mathrm{L}^{-1}\right) \\
(95 \% \text { fiducial limits })\end{array}$ & $\begin{array}{c}96 \mathrm{~h} \mathrm{LC}_{50}\left(\mathrm{mg} \mathrm{L}^{-1}\right) \\
(95 \% \text { fiducial limits })\end{array}$ \\
\hline Cinnamon $\left(\mathrm{SD}^{1}\right)$ & 10.48 & 10.48 \\
& $(10.01-10.89)$ & $(10.01-10.89)$ \\
Cinnamon $\left(\mathrm{SE}^{2}\right)$ & 11.55 & 11.55 \\
Cinnamon $\left(\mathrm{SFE}^{3}\right)$ & $(8.73-13.23)$ & $(8.73-13.23)$ \\
\hline
\end{tabular}

${ }^{\mathrm{a}} \mathrm{LC}_{50}$ values were greater than $10 \mathrm{mg} \mathrm{L}{ }^{-1}$. ${ }^{1}$ Steam distillation, ${ }^{2}$ Solvent extraction with hexane, ${ }^{3}$ Supercritical Fluid Extraction

Table 2 Acute toxicity of emulsifiable concentrates of cinnamon essential oils to carps (Cyprinus carpio)

\begin{tabular}{ccc}
\hline \hline $\begin{array}{c}\text { Emulsifiable } \\
\text { concentrates }\end{array}$ & $\begin{array}{c}48 \mathrm{~h} \mathrm{LC}_{50}\left(\mathrm{mg} \mathrm{L}^{-1}\right) \\
(95 \% \text { fiducial limits })\end{array}$ & $\begin{array}{c}96 \mathrm{~h} \mathrm{LC}_{50}\left(\mathrm{mg} \mathrm{L}^{-1}\right) \\
(95 \% \text { fiducial limits })\end{array}$ \\
\hline Cinnamon $\left(\mathrm{SD}^{1}\right)$ & 8.37 & 8.26 \\
& $(7.69-9.25)$ & $(7.57-9.10)$ \\
Cinnamon $\left(\mathrm{SE}^{2}\right)$ & 6.30 & 6.14 \\
& $(5.45-6.76)$ & $(4.90-6.65)$ \\
Cinnamon $\left(\mathrm{SFE}^{3}\right)$ & 6.16 & 6.03 \\
& $(5.33-6.56)$ & $(4.57-6.47)$ \\
\hline
\end{tabular}

${ }^{1}$ Steam distillation, ${ }^{2}$ Solvent extraction with hexane, ${ }^{3}$ Supercritical Fluid Extraction

정유를 용매 추출법으로 얻었을 때 이들의 독성은 수증기 추출 법으로 추출한 정유보다 독성이 낮았음을 확인하였다. 또한 초 임계 추출로 추출한 정유의 경우 $\mathrm{LC}_{50}$ 값이 $10 \mathrm{mg} \mathrm{L}^{-1}$ 이상임 으로 독성의 강도 더 낮아졌음을 측정하였다. 위의 결과를 종 합하여 보면 각 추출법에 따라서 추출되는 정유 성분의 차이가 있으며 이는 급성 어독성과 관련되었다. 수증기증류법으로 추출 한 정유의 경우 독성을 일으키는 성분이 가장 많이 추출된 것 으로 사료된다.

계피정유 오일의 급성독성 평가는 친환경 살충소재의 활용을 위하여 랫드를 이용하여 급성경구독성, 급성경피독성, 피부자극 성 및 안점막자극성 실험을 실시한 바 있다[14]. 이 실험을 통 하여 저자들은 계피오일의 급성경구독성이 $\mathrm{LD}_{50}$ 값이 2,000 $\mathrm{mg} / \mathrm{kg}$ 이상임을 확인하였고 급성경피독성실험 결과 또한 $\mathrm{LD}_{50}$ 값이 $4,000 \mathrm{mg} / \mathrm{kg}$ 이상이었다. 더불어 안점막실험 결과 중도의 자극성을 나타내었지만 세척후 자극성은 사라졌다고 보고되었 다. 이러한 결과를 토대로 온혈동물인 랫드에 대한 계피정유의 급성독성은 비교적 낮은 것으로 판명되었고 피부자극 및 안점 막자극성이 있다고 보여진다[14]. 또한, 계피정유의 생태독성평 가 결과가 물벼룩, 송사리, 꿀벌, 지렁이 등을 이용하여 보고되 었다[15]. 이중 계피정유의 송사리에 대한 급성독성은 $\mathrm{LC}_{50}$ 값 이 $7.5 \mathrm{mg} \mathrm{L}^{-1}$ 으로 나타났고 이는 본 실험 결과 값과 크게 다 르지 않은 값이었으며 이는 시험 종의 차이에서 기인한 것으로 여겨진다.

잉어에 대한 계피정유 유제의 급성어독성은 Table 2에 나타 내었다. 수증기 증류법으로 추출된 정유는 48 시간 동안 잉어에 노출되었을 때 $\mathrm{LC}_{50}$ 값이 $8.37 \mathrm{mg} \mathrm{L}^{-1}$ 수준이었으며 96시간에 서 $8.26 \mathrm{mg} \mathrm{L}^{-1}$ 으로 나타났다. 이는 48 시간 이후 96 시간까지 치 사개체가 더 발생하였음을 의미한다. 핵산을 이용한 용매 추출 법으로 획득한 계피정유의 경우 48 시간 동안 노출시켰을 때 
Table 3 Acute toxicity of granules of cinnamon essential oils to carps (Cyprinus carpio)

\begin{tabular}{ccc}
\hline \hline Granules & $\begin{array}{c}48 \mathrm{~h} \mathrm{LC}_{50}\left(\mathrm{mg} \mathrm{L}^{-1}\right) \\
(95 \% \text { fiducial limits })\end{array}$ & $\begin{array}{c}96 \mathrm{~h} \mathrm{LC}_{50}\left(\mathrm{mg} \mathrm{L}^{-1}\right) \\
(95 \% \text { fiducial limits })\end{array}$ \\
\hline Cinnamon $\left(\mathrm{SD}^{1}\right)$ & 9.42 & 9.19 \\
Cinnamon $\left(\mathrm{SE}^{2}\right)$ & $(8.76-10.41)$ & $(8.59-9.92)$ \\
Cinnamon $\left(\mathrm{SFE}^{3}\right)$ & $-^{\mathrm{a}}$ & - \\
\hline
\end{tabular}

${ }^{\mathrm{a}} \mathrm{LC}_{50}$ values were greater than $10 \mathrm{mg} \mathrm{L}{ }^{-1}$. ${ }^{1}$ Steam distillation, ${ }^{2}$ Solvent extraction with hexane, ${ }^{3}$ Supercritical Fluid Extraction

$\mathrm{LC}_{50}$ 값이 $6.30 \mathrm{mg} \mathrm{L}^{-1}$ 이었으며 96 시간 노출시켰을 때의 $\mathrm{LC}_{50}$ 값은 6.14 로 역시 $\mathrm{LC}_{50}$ 값이 감소되었다. 이러한 결과를 토대 로 계피 정유의 유제 형태는 용매 추출법으로 추출된 정유의 형태가 수증기 추출법으로 추출한 정유보다 더 강한 독성을 나 타내었다. 또한 초임계 추출로 추출한 정유의 경우 $\mathrm{LC}_{50}$ 값이 $6.16 \mathrm{mg} \mathrm{L}^{-1}$ 이었으며 96 시간의 $\mathrm{LC}_{50}$ 값은 $6.03 \mathrm{mg} \mathrm{L}^{-1}$ 으로 시간 이 경과함에 따라 독성이 더 강하게 나타났고 초임계 추출로 추출한 정유의 성분들 중에 강한 독성을 일으키는 성분이 유제 형태로 존재할 때 보다 더 효과적으로 독성을 나타내고 있음을 알 수 있었다. 이러한 결과는 향후 원제를 제제화하여 사용할 때 환경 중 수서생태계에 미치는 영향을 필히 실시해야 함을 입증하였다.

이와 비슷하게 농업해충인 배추좀나방에 대한 계피정유를 함 유한 친환경유기농자재 소재 중 이들의 유제에 대한 생태독성 평가를 실시하여 잉어에 대한 급성독성이 $1.9 \mathrm{mg} \mathrm{L}^{-1}$ 로 나타나 어독성 II급으로 판명된 바 있다[16]. 그러나. 이 제형은 계피 정유 만으로 유효성분을 구성하지 않고 후추에서 유래된 정유 를 함유함으로써 잉어에 대한 급성어독성이 계피정유 만으로 발 생한 독성으로 보기에는 무리가 있다고 보여진다.

잉어에 대한 계피정유 입제의 급성어독성은 Table 3에 나타 내었다. 수증기 증류법으로 추출된 정유 만이 독성을 나타내었 고 48 시간 동안 잉어에 노출되었을 때 $\mathrm{LC}_{50}$ 값이 $9.42 \mathrm{mg} \mathrm{L}^{-1}$ 수준으로 나타내었다. 일한 시료를 96시간 동안 노출시켰을 때 $\mathrm{LC}_{50}$ 값은 $9.19 \mathrm{mg} \mathrm{L}$ 으로 나타났다. Table 3의 결과는 수증기 추출 정유가 입제화 되었을 때 그 독성이 다른 추출법으로 추 출한 것들 보다 독성이 더 강하게 발생함을 알 수 있었다.

제브라피쉬를 이용한 만성 독성을 측정하기 위하여 우선 배 아의 부화율 및 치어에 대한 계피 정유 유제의 급성 어독성을 실험하였다. 수증기 추출법으로 추출한 계피 정유 유제 형태만 을 본 실험에 사용하였고 이유는 다른 제제 형태나 또는 다른 추출방법으로 얻은 정유 보다 더 강한 살충효과를 나타낸 바 있기 때문이다[7].

수증기 추출법으로 추출한 계피 정유 유제의 제브라피쉬 배 아에 대한 부화율에 미치는 영향은 Table 4에 나타내었다. 대 조군의 부화율이 $86.7 \%$ 였으며 정유를 뺀 유제에 노출된 제브 라피쉬의 부화율은 $93.6 \%$ 였으며 두 실험군 간의 유의성은 발 견되지 않았다. 수증기 추출법으로 추출한 계피 정유 유제의 처 리 농도는 $500 \mathrm{mg} \mathrm{L}^{-1}$ 였으며 이 때 부화율은 $84.4 \%$ 로써 두가 지 다른 대조군과의 비교에서 통계학적으로 유의성이 없었다. 따라서, 이 처리 농도 범위에서는 수증기 추출법으로 추출한 계 피 정유 유제는 제브라피쉬 배아의 부화에 독성을 나타내지 않
Table 4 Hatching rates of emulsifiable concentrates of cinnamon essential oils obtained using steam distillation to zebrafish embryos (Danio rerio)

\begin{tabular}{ccc}
\hline \hline Sample & Concentration $\left(\mu \mathrm{g} \mathrm{L}^{-1}\right)$ & Hatching rates $(96 \mathrm{~h})$ \\
\hline Control (negative) & water & $86.7 \pm 8.79^{\mathrm{a}}$ \\
Control (positive) & without essential oil & $93.6 \pm 3.81^{\mathrm{a}}$ \\
Cinnamon & 10 & $94.7 \pm 2.48^{\mathrm{a}}$ \\
& 50 & $90.3 \pm 7.15^{\mathrm{a}}$ \\
& 100 & $88.9 \pm 6.97^{\mathrm{a}}$ \\
& 500 & $87.7 \pm 6.92^{\mathrm{a}}$ \\
& $54.4 \pm 3.86^{\mathrm{a}}$ \\
\hline
\end{tabular}

${ }^{a}$ Same letters in the column means no significantly different between treatments

Table 5 Acute and chronic toxicities and hatching rates of emulsifiable concentrates of cinnamon essential oils obtained using steam distillation to zebrafishes (Danio rerio)

\begin{tabular}{ccc}
\hline \hline toxicity & $\begin{array}{c}48 \mathrm{~h} / 15 \text { day }^{\mathrm{a}} \mathrm{LC}_{50}\left(\mathrm{mg} \mathrm{L}^{-1}\right) \\
(95 \% \text { fiducial limits })\end{array}$ & $\begin{array}{c}96 \mathrm{~h} / 45 \text { day }^{\mathrm{b}} \mathrm{LC}_{50}\left(\mathrm{mg} \mathrm{L}^{-1}\right) \\
(95 \% \text { fiducial limits })\end{array}$ \\
\hline Acute & 8.62 & 8.62 \\
Chronic & $(7.52-9.63)$ & $(7.52-9.63)$ \\
\hline
\end{tabular}

a Duration of experiments for acute $(48 \mathrm{~h}) /$ chronic (15 day) toxicities using zebrafishes

${ }^{a}$ Duration of experiments for acute $(96 \mathrm{~h}) /$ chronic (45 day) toxicities using zebrafishes

${ }^{\mathrm{c}} \mathrm{LC}_{50}$ values were greater than $0.5 \mathrm{mg} \mathrm{L}^{-1}$

았다.

제브라피쉬에 대한 수증기 추출법으로 추출한 계피 정유 유 제의 급성독성은 Table 5에 나타내었다. 제브라피쉬에 대한 48 시간 및 96 시간의 $\mathrm{LC}_{50}$ 값은 동일하였으며 그 값은 8.62 $\mathrm{mg} \mathrm{L}^{-1}$ 이었다. 이 값은 잉어에 대한 값과 유사하였다(Table 3). 이러한 결과를 토대로 잉어가 제브라피쉬 보다 더 계피 정유에 대하여 민감함을 알 수 있었다. 그러나 45일 동안 시행하였던 만성독성 결과는 표 5에서와 같이 치사개체가 발견되지 않았다. 향후 수증기 추출법으로 추출한 계피 정유 유제의 잉어를 이용 한 만성독성 실험 및 꿀벌에 대한 알파파 엽상잔류독성 실험을 실시하여 이들 정유에 오랜 노출 시간 노출된 시험종 어류의 반응과 살포 후 엽에 잔류하는 시험물질의 독성을 평가하는 것 이 필요하다고 보여진다.

\section{초 록}

계피정유를 유제 및 입제로 제형화한 후 이들의 생태독성을 측 정하였다. 잉어를 이용한 급성독성에 사용된 계피정유는 수증기 증류법, 핵산을 이용한 용매추출법 및 초임계 추출법을 이용하 여 얻었고 이들의 유제 및 입제의 생태독성학적 영향은 반수치 사농도 $\left(\mathrm{LC}_{50}\right)$ 를 구하여 평가하였다. 유제 중 초임계추출법으로 얻은 정유를 함유한 제형이 잉어에 대하여 가장 높은 독성을 나타내었다. 입제 중 수증기 증류법으로 추출한 계피정유를 함 유한 입제가 잉어에 대하여 가장 높은 급성독성을 보였다. 이 러한 결과는 3 급 어독성에 해당되는 것으로 환경 중 사용에는 
문제가 없다고 사료된다. 잉어를 이용하여 얻은 급성독성 결과 와 같이 제브라피쉬를 사용하여 얻은 급성독성 결과 값들은 유 사하였다. 수증기증류법으로 얻은 계피정유를 함유한 유제에 노 출된 제브라피쉬를 이용한 만성독성은 45 일 동안 $500 \mathrm{mg} \mathrm{L}^{-1}$ 수준에서 독성이 관측되지 않았다. 따라서, 계피정유의 유제 및 입제의 급만성 어독성은 친환경제재로 사용하기에 적합한 것으 로 사료된다.

Keywords Acute toxicity - Chronic toxicity - Cinnamon essential oil · Cyprinus carpio, Danio rerio - Emulsifiable concentrate · Granules

감사의 글 본 연구는 농촌진흥청 공동연구사업 (세부과제명: 고수, 길초근 등 유래 기능성 물질 이용 주요 농작물 해충 방제제 개발, 과제번호: PJ011983032016)의 지원으로 이루어진 것이며, 이에 감사 드립니다.

\section{References}

1. Ranasinghe P, Pigera S, Sirimal Premakumara GA, Galappaththy P, Constantine GR, Katulanda P (2013) Medicinal properties of true cinnamon (Cinnamomum zeylanicum): a systematic review. BMC Complement Altern Med 13: 275

2. Baratta MT, Dorman HJD, Deans SG, Figueiredo AC, Barroso JG Ruberto G (1998) Antimicrobial and antioxidant properties of some commercial essential oils. Flavour Fragr J 13: 235-244

3. Carmo ES, Lima EDO, De Souza EL, De Sousa FB (2008) Effect of cinnamomum zeylanicum blume essential oil on the growth and morphogenesis of some potentially pathogenic aspergillus species. Braz $\mathrm{J}$ of Microbiol 39: 91-97

4. Hassan SA, Barthwal R, Nair MS, Haque SS (2012) Aqueous bark extract of Cinnamomum zeylanicum: a potential therapeutic agent for streptozotocin-induced type 1 diabetes mellitus (T1DM) rats. Trop J Pharm Res 11: 429-435

5. Zhang Y, Liu X, Jiang P, Quek SY (2016) Antibacterial activity and mechanism of cinnamon essential oil against Escherichia coli and Staphylococcus aureus. Food Control 59: 282-289

6. Cansian RL, Astolfi V, Cardoso RI, Paroul N, Roman SS, Mielniczki-
Pereira AA, Pauletti GF, Mossi AJ (2015) Insecticidal and repellent activity of the essential oil of Cinnamomum camphora var. linaloolifera Y. Fujita (Ho-Sho) and Cinnamomum camphora (L.) J Presl. var. hosyo (Hon-Sho) on Sitophilus zeamais Mots. (Coleoptera, Curculionedae). Rev Bras P1 Med Campinas 17: (Suppl. 1), 769-773

7. Park B, Lee MJ, Lee SK, Lee SB, Jeong IH, Park SK, Jeon YJ, Lee HS (2017) Insecticidal activity of coriander and cinnamon oils prepared by various methods against three species of agricultural pests (Myzus persicae, Teyranychus urticae and Plutella xylostella). J Appl Biol Chem 60(2): 137-140

8. Natrajan D, Srinivasan S, Sunder K, Ravindran A (2015) Formulation of essential oil-loaded chitosan-alginate nanocapsules. J Food Drug Anal 23: 560-568

9. Koul O, Wallia S, Dhaliwal GS (2008) Essential oils as green pesticides: potential and constraints. Biopestic Int 4: 63-84

10. Tanoviæ $B$, Gašiæ $S$, Hrustiæ $J$, Mihajloviæ $M$, Grahovac $M$, Delibašiæ G, Stevanoviæ M (2013) Development of a thyme essential oil formulation and its effect on Monilinia fructigena. Pestic Phytomed 28: 273-280

11. Biddeci G, Cavallaro G, Di Blasi F, Lazzara G, Massaro M, Miloto S, Parisi F, Riela S, Spinelli G (2016) Halloysite nanotubes loaded with peppermint essential oil as filler for functional biopolymer film. Carbohydr Polym 152: 548-557

12. You AS, Jeong M, Hong SS, Park KH, Chang HS, Lee JB, Park JY (2012) Acute ecotoxicity of 3 emulsifiable concentrates containing garlic extract, Zanthoxylum extract, and lemon grass oil originated from plant. Korean J Pestic Sci 16: 376-382

13. Nam TH, Jeon HJ, Kim K, Choi Y, Lee SE (2016) Acute toxicity of emulsifiable concentrate of coriander essential oils against Cyprinus carpio. Korean J. Environ Biol 34: 208-211

14. Jeong M, Kwon MJ, Park SJ, Hong SS, Park KH, Park JE, Yeon SH (2010) Evaluation of acute toxicity of plant extracts, lavender, lemon eucalyptus and cassia essential oil. Korean J Pestic Sci 14: 339-346

15. You AS, Choi YW, Jeong MH, Hong SS, Park YK, Jang HS, Park JY, Park KH (2011) Acute ecotoxicity evaluation of thyme white, clove bud, cassia, lavender, lemon eucalyptus essential oil of plant extracts. Korean J Pestic Sci 15: 350-356

16. You AS, Jeong MH, Hong SS, Chang HS, Lee JB, Park KH, Lee YM, Ihm Y (2013) Acute ecototoxicity of environmental-friendly organic agro-materials containing pepper extract, cassia oil, lavender oil for control of diamondbackmoth. Korean J Pestic Sci 17: 343-349 